\title{
Evolução do processo biodegradativo em lisímetros com diferentes composiç̧̃̃es de resíduos sólidos urbanos
}

\section{Biodegradation process evolution in lysimeters with different municipal solid waste compositions}

\author{
Data de entrada: \\ 09/04/2020 \\ - Data de aprovação: \\ $13 / 07 / 2020$
}

Maria Josicleide Felipe Guedes $1 *$ | Francisco Gleson dos Santos Moreira ${ }^{2}$ |

Luís Antônio Oliveira Nunes ${ }^{3}$ | William de Paiva ${ }^{4}$ | Veruschka Escarião Dessoles Monteiro ${ }^{5}$ |

DOI: https://doi.org/10.36659/dae.2021.080

Márcio Camargo de Melo

ORCID ID

Guedes MJF (D) https://orcid.org/0000-0002-1028-1040

Moreira FGS (D) https://orcid.org/0000-0003-2964-2552

Nunes LAO (D) https://orcid.org/0000-0002-1900-4461
Paiva W (D) https://orcid.org/0000-0003-0220-1247

Monteiro VED (iD) https://orcid.org/0000-0002-7714-5692

Melo MC (D) https://orcid.org/0000-0001-6215-8100

\section{Resumo}

O estudo do comportamento dos resíduos sólidos urbanos (RSU) em escala reduzida tem sido utilizado para aprimorar o entendimento da biodegradação desses resíduos, possibilitando o redirecionamento de projetos em aterros. Nesse contexto, objetivou-se analisar a evolução do processo biodegradativo em lisímetros com diferentes composições de RSU, submetidas às condições hidrometeorológicas do semiárido brasileiro. Para tanto foram confeccionados 9 lisímetros com diferentes composições e massas de resíduos, sendo construídos com 100\% de resíduos sólidos orgânico (RSO), 70\% (RSU intermediário $_{\text {) }}$ e 40\% (RSU). Verificou-se, em 270 dias de monitoramento, que a maior geração de lixiviado ocorreu nos lisímetros RSO, os quais apresentaram maiores massas de resíduos e umidade inicial. A reduzida geração de lixiviado nos lisímetros RSU e a não geração no conjunto RSU estão associadas à maior heteregeneidade desses resíduos, implicando em baixas densidades, em comparação aos lisímetros RSO.

Palavras-chave: Semiárido. Células experimentais. Lixiviado.

\section{Abstract}

The study of the behavior of municipal solid waste (MSW) on a small scale was used to improve the understanding of waste biodegradation, enabling the redirection of landfill projects. In this context, the objective was to analyze the evolution of the biodegradative process in lysimeters with different compositions of MSW, submitted to the hydrometeorological conditions of the Brazilian semiarid. For that, 9 lysimeters were made with different compositions and masses of residues, be-

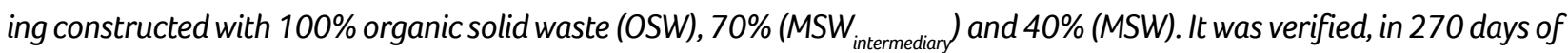
monitoring, that the largest generation of leachate occurred in OSW lysimeters, which presented residues masses and initial humidity higher. The reduced leachate generation in the MSW intermediary lysimeters and the non-generation in the MSW set is associated with greater heterogeneity of these residues, implying low densities, compared to the OSW lysimeters.

Keywords: Semiarid. Experimental cells. Leachate.

\footnotetext{
${ }^{1}$ Universidade Federal Rural do Semi-Árido - Mossoró - Rio Grande do Norte - Brasil.

2 Universidade Federal do Ceará - Fortaleza - Ceará - Brasil.

${ }^{3}$ Universidade Federal do Piauí - Teresina - Piauí - Brasil.

${ }^{4}$ Universidade Estadual da Paraíba - Campina Grande - Paraíba - Brasil.

${ }^{5}$ Universidade Federal de Campina Grande - Campina Grande - Paraíba - Brasil.

* Autora correspondente: mjosicleideaufersa.edu.br.
} 


\section{INTRODUÇÃO}

O processo biodegradativo dos resíduos sólidos urbanos (RSU) em aterros sanitários evolui de acordo com as condições internas. Essas condições podem ser impostas por meio da atividade biológica ou por fenômenos externos ao processo. Vários fatores influenciam esse processo, incluindo: presença de inibidores (a exemplo da amônia), temperatura, $\mathrm{pH}$, teor de umidade, composição dos resíduos, geometria e operação do aterro etc. (LASKRI e NEDJAH, 2015; SETHI; KOTHIYAL; NEMA, 2013; RAPOSO et al., 2011; CHEN; CHENG; CREAMER, 2008; BARLAZ et al., 1990).

Um dos parâmetros mais críticos que afeta a biodegradação dos RSU é o teor de umidade. 0 aumento da umidade dos resíduos eleva o transporte de nutrientes, a solubilização da matéria orgânica e a mobilização de microrganismos em microambientes, além de diluir a concentração de inibidores (MORA-NARANJO et al., 2004).

Os aterros sanitários operados por tecnologia convencional, denominada "dry tomb" ("túmulos secos"), partem do princípio de que os resíduos sólidos são "sepultados" em um revestimento de plástico e/ou cobertura de solo argiloso compactado (LEE; JONES-LEE, 2015). O processo de estabilização dos resíduos é muito lento, devido à umidade insuficiente e à sua distribuição desigual nesses aterros (SETHI; KOTHIYAL; NEMA, 2013). O'Leary e Tchobanoglous (2002) afirmam que aterros sanitários com teor de umidade insuficiente foram encontrados em uma condição "mumificada", com papel de jornal de décadas ainda legível.

Como mencionado, o processo biodegradativo dos RSU é dependente, também, da composição dos resíduos dispostos no aterro. Laskri e Nedjah (2015) compararam a digestão anaeróbia de dois substratos diferentes, resíduos biodegradáveis de um aterro sanitário e lodo de estação de tratamento de águas residuárias, nas mesmas condições de operação. Os autores verificaram que, durante a fase metanogênica, quanto maior a concentração de material orgânico biodegradável, mais elevada a produção de biogás em ambos os casos.

De acordo com Sanchez (2009), a lignocelulose é um dos principais componentes dos RSU, constituída principalmente por polímeros, celulose, hemicelulose e lignina. Muitos microrganismos são capazes de degradar e utilizar a celulose e a hemicelulose como fontes de carbono e de energia, enquanto a lignina, principal componente do papel, é altamente resistente à biodegradação anaeróbia (SETHI; KOTHIYAL; NEMA, 2013; JAYASINGHE et al., 2011; HIGUCHI, 2006).

Sethi, Kothiyal e Nema (2013) citam a densidade de compactação dos resíduos e sua importância, não apenas porque define a quantidade de resíduos depositada em um determinado volume, mas em virtude da manutenção da distribuição uniforme da umidade e o fluxo adequado de fluido nos aterros. Segundo O'Leary e Tchobanoglous (2002), o aumento da densidade do material aterrado irá diminuir a disponibilidade de umidade para algumas partes dos resíduos e, assim, reduzir a taxa de bioconversão.

De acordo com Dayanthi (2003), os resíduos moderadamente compactados se degradam mais rapidamente do que os resíduos densamente compactados. $\mathrm{O}$ autor cita que a densidade de compactação superior a $500 \mathrm{~kg} \cdot \mathrm{m}^{-3}$ reduz a capacidade de lixiviação. Além disso, a compactação de resíduos em camadas finas aumenta a biodegradação dos resíduos devido à melhor distribuição da umidade.

Ressalta-se que, no ambiente de um aterro sanitário, sua dinâmica operacional, os elevados custos e o número de variáveis envolvidas neste tipo de empreendimento limitam um controle mais preciso do processo biodegradativo. Nessa perspectiva, o estudo do comportamento de aterros em células experimentais de diferentes escalas 
pode ser bastante útil. Assim, no presente artigo foi analisada a evolução do processo biodegradativo em lisímetros preenchidos com diferentes composições de RSU, no município de Campina Grande-PB, submetidas às condições hidrometeorológicas do semiárido brasileiro.

\section{MATERIAIS E MÉTODOS}

\subsection{Caracterização da área de estudo}

O município de Campina Grande localiza-se no estado da Paraíba, região Nordeste do Brasil, sob coordenadas geográficas de 7¹3'50" de latitude Sul e $35^{\circ} 52^{\prime} 52^{\prime \prime}$ a oeste de Greenwich. Possui uma população estimada de 409.731 habitantes (IBGE, 2019) e uma geração de resíduos de RSU em torno de $500.000 \mathrm{~kg} \mathrm{dia}^{-1}$ (ECOSOLO, 2016). Destaca-se que a disposição final dos RSU de Campina Grande-PB é realizada em um aterro sanitário privado, desde julho de 2015, a $10 \mathrm{~km}$ da área urbana do município, sob coordenadas geográficas $7^{\circ} 16^{\prime} 38^{\prime \prime}$ latitude Sul e $36^{\circ} 00^{\prime} 51^{\prime \prime}$ a oeste de Greenwich.
Em termos hidrometeorológicos, caracteriza-se por condições adversas, típicas do semiárido brasileiro, com precipitação e evaporação média anual de 748 e $1.417 \mathrm{~mm}^{\text {ano }}{ }^{-1}$, respectivamente (PARAÍBA, 2001), o que favorece um déficit hídrico ao longo de vários meses do ano.

\subsection{Aspectos construtivos dos lisímetros}

Foram confeccionados 9 lisímetros de policloreto de vinila (PVC), sendo esses divididos, igualmente, em 3 conjuntos, todos com altura de $1 \mathrm{~m}$, porém cada bateria era composta de um lisímetro de 0,150, 0,200 e 0,250 m de diâmetro. Cada lisímetro foi concebido de maneira a contemplar: i) uma camada de base de solo compactado de 0,10 m, apoiada em uma base de madeira de demolição, de espessura aproximada de 0,02 m, devidamente impermeabilizada; ii) camada de resíduos sólidos de $0,60 \mathrm{~m}$; e iii) camada de cobertura final de solo compactado de 0,20 m (Fig. 1).

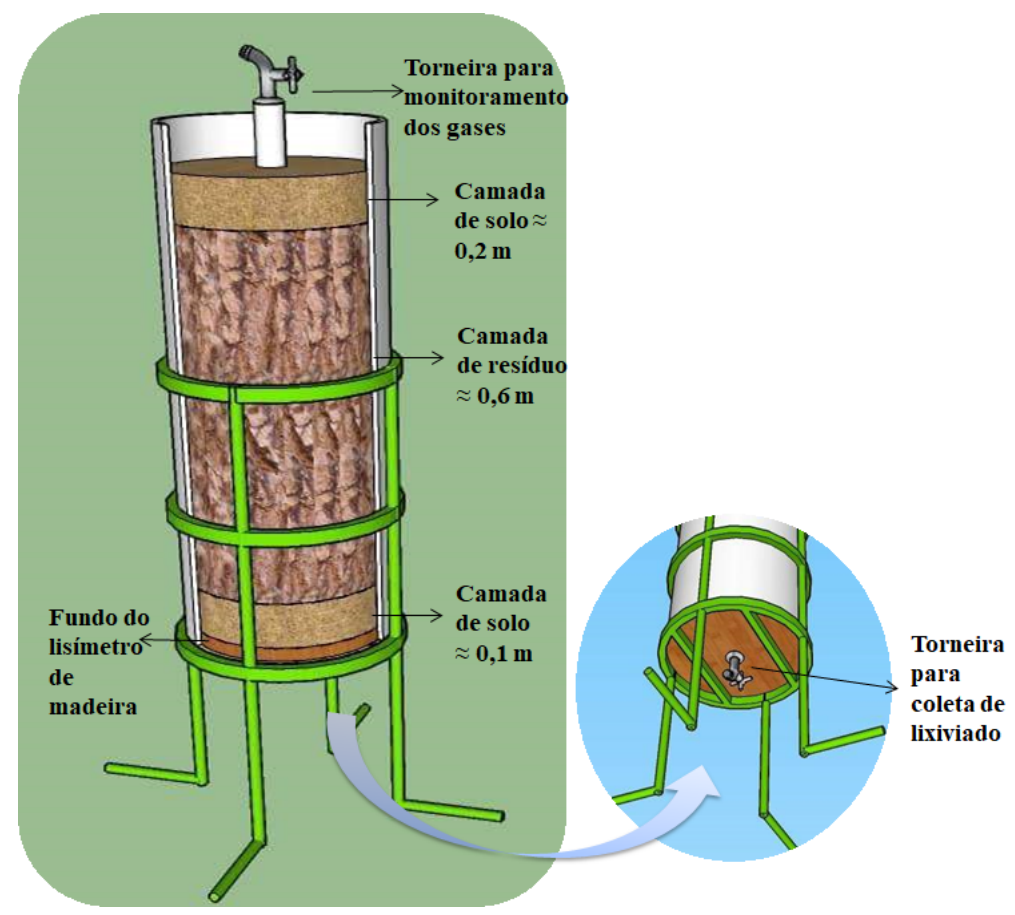

Figura 1 - Croqui dos lisímetros de PVC Fonte: Acervo da pesquisa (2016) 
Todos os lisímetros foram instrumentados com sistema de drenagem de lixiviado (Fig. 1). Ressalta-se que os solos utilizados nos lisímetros foram os mesmos utilizados na operação do Aterro Sanitário em Campina Grande-PB.

\subsection{Composição gravimétrica dos resíduos nos lisímetros}

A composição dos resíduos sólidos contidos nos lisímetros foi baseada em um planejamento de experimentos, por meio do qual foram definidos limites máximo, médio e mínimo de percentual de matéria orgânica, sendo estes de 100, 70 e $40 \%$, respectivamente. O limite mínimo de $40 \%$ de matéria orgânica (MO) partiu do pressuposto da composição gravimétrica dos resíduos em países em desenvolvimento, como é o caso do Brasil (ABRELPE, 2014).

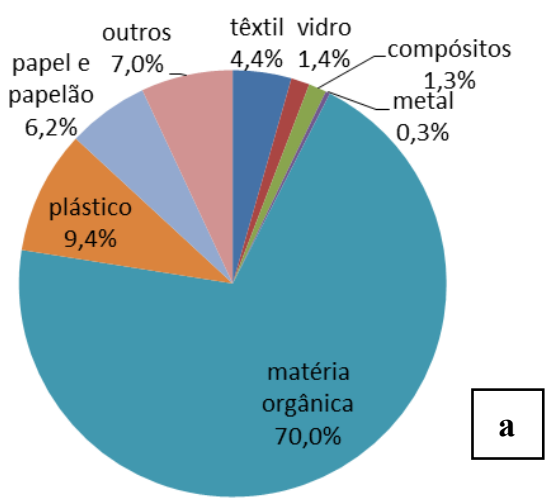

A partir do planejamento dos experimentos, obteve-se a seguinte porcentagem de matéria orgânica nos lisímetros: i) L1, L2 e L3, lisímetros constituídos em sua totalidade (100\%) de matéria orgânica (denominado de conjunto RSO); ii) L4, L5 e L6, lisímetros com $70 \%$ de matéria

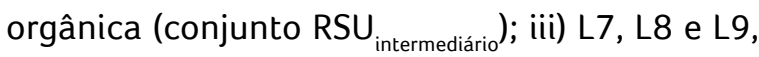
lisímetros com um percentual de $40 \%$ de matéria orgânica (conjunto RSU).

A composição dos resíduos para os lisímetros $L 4$ a L9 foi obtida proporcionalmente à composição gravimétrica dos RSU de Campina Grande-PB, definida em Araújo Neto (2016), na qual 46,5\% dos resíduos são compostos por material putrescível. Partindo desse pressuposto, a composição gravimétrica para os lisímetros L4 a L6 (contemplando $70 \%$ de matéria orgânica) e para os lisímetros L7 a L9 (contemplando $40 \%$ de matéria orgânica) são ilustradas nas Fig. 2a e 2b, respectivamente.

Figura 2 - Composição gravimétrica dos resíduos nos lisímetros: (a) 70\% de matéria orgânica (RSU e (b) $40 \%$ de matéria orgânica (RSU) Fonte: Dados da pesquisa (2016)

\subsection{Preparação das amostras de resíduos}

Os resíduos coletados para compor as amostras foram provenientes do Aterro Sanitário em Campina Grande-PB, dispostos em um dia anterior à operação de enchimento dos lisímetros. Para a preparação das amostras, os resíduos foram destinados ao pátio de poda do empreendimen- to (Fig. 3a). No pátio, os resíduos foram segregados em função das frações de matéria orgânica, plástico, papel e papelão, têxtil, vidro, compósitos, metal e outros, conforme exemplos apresentados nas Fig. 3b e 3c.

Cada fração foi pesada (Fig. 3d) até ser atingida a massa necessária à obtenção das compo- 
sições de 70 e $40 \%$ de matéria orgânica (Tabela 1). Sendo assim, foram formadas duas pilhas de resíduos, uma para cada composição desejada, com uma massa de $70 \mathrm{~kg}$ cada. Vale salientar que os resíduos passaram por um processo de redução de sua granulometria por processo manual e homogeneização (Fig. 3e), para posterior enchimento dos lisímetros.

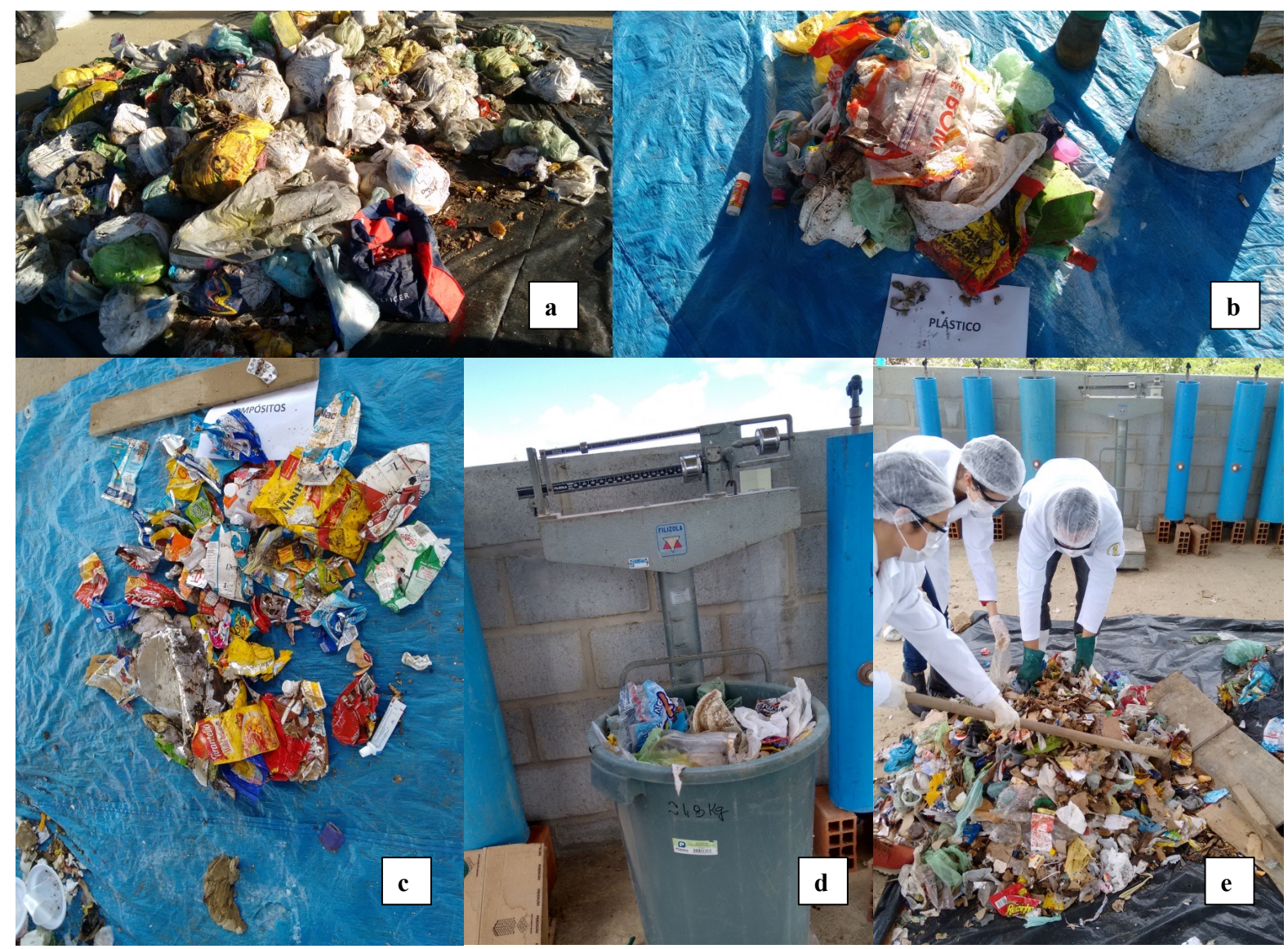

Figura 3 - Preparação das amostras para preenchimento dos lisímetros: (a) resíduos provenientes do aterro sanitário em Campina Grande-PB, (b) segregação das frações de resíduos - plásticos, (c) segregação das frações de resíduos compósitos, (d) pesagem das frações e (e) homogeneização da pilha de resíduos Fonte: Acervo da pesquisa (2016)

Tabela 1 - Distribuição em massa das frações de resíduos para os conjuntos de lisímetros

\begin{tabular}{|c|c|c|}
\hline \multirow{2}{*}{$\begin{array}{l}\text { Frações } \\
\text { de resíduos }\end{array}$} & Conjunto $\mathrm{RSU}_{\text {intermediário }}{ }^{1}$ & Conjunto $\mathrm{RSU}^{2}$ \\
\hline & \multicolumn{2}{|c|}{ Massa de resíduos $(\mathbf{k g})$} \\
\hline Têxtil sanitário & 3,1 & 6,2 \\
\hline Vidro & 1,0 & 2,0 \\
\hline Compósitos & 0,9 & 1,9 \\
\hline Metal & 0,2 & 0,5 \\
\hline Material putrescível & 49,0 & 28,0 \\
\hline Plástico & 6,6 & 13,1 \\
\hline Papel e papelão & 4,3 & 8,6 \\
\hline Outros & 4,9 & 9,7 \\
\hline Total & 70,0 & 70,0 \\
\hline
\end{tabular}

${ }^{1}$ Conjunto de lisímetros constituídos por resíduos sólidos urbanos com $70 \%$ de matéria orgânica (RSU ). ${ }^{2}$ Conjunto de lisímetros constituídos por resíduos sólidos urbanos com $40 \%$ de matéria orgânica (RSU).

Fonte: Dados da pesquisa (2016) 
Procedida a montagem, os lisímetros foram expostos às condições meteorológicas locais. Posteriormente, houve a necessidade de vedação dos lisímetros, após 150 dias, em função da formação de trincas na camada de cobertura de solo compactado. Sendo assim, os lisímetros passaram por duas etapas operacionais: i) 150 dias iniciais, a qual compreendeu o período chuvoso de Campina Grande-PB, e ii) 150 a 270 dias, sem aporte de precipitação.

\subsection{Configuração dos lisímetros}

Na Tabela 2 são apresentados detalhes da configuração dos 9 lisímetros. Como padrão para o enchimento das células experimentais, procedeu-se de maneira a obter densidades mais próximas possíveis para os 3 lisímetros de cada bateria. Nesse sentido, para a bateria de lisímetros L1 a L3, por exemplo, no momento do enchimento, a célula experimental foi pesada para que se obtivesse, exatamente, a massa de resíduos correspondente à altura de $0,60 \mathrm{~m}$, delimitada na Fig. 1. A partir da densidade obtida para o primeiro lisímetro de cada conjunto, replicou-se de forma semelhante para os demais (Tabela 2).

Tabela 2 - Configurações dos lisímetros.

\begin{tabular}{|c|c|c|c|c|c|c|c|c|c|}
\hline \multirow{2}{*}{ Configuração } & \multicolumn{3}{|c|}{$\mathrm{RSO}^{1}$} & \multicolumn{3}{|c|}{$\mathrm{RSU}_{\text {intermediário }}{ }^{2}$} & \multicolumn{3}{|c|}{$\mathrm{RSU}^{3}$} \\
\hline & $\mathrm{L}^{4}{ }^{4}$ & $L 2^{4}$ & $\mathrm{~L}^{3}{ }^{4}$ & $\mathrm{L4}^{4}$ & L5 $^{4}$ & L6 $6^{4}$ & $\mathrm{~L}^{4}$ & $\mathrm{~L}^{4}$ & L9 $9^{4}$ \\
\hline$A_{\text {superficial }}\left(x 10^{-3} \mathrm{~m}^{2}\right)$ & 17,67 & 31,42 & 49,09 & 17,67 & 31,42 & 49,09 & 17,67 & 31,42 & 49,09 \\
\hline $\mathrm{A} / \mathrm{V}\left(\mathrm{m}^{-1}\right)$ & 1,7 & 1,7 & 1,7 & 1,7 & 1,7 & 1,7 & 1,7 & 1,7 & 1,7 \\
\hline Massa de resíduos (kg) & 11,1 & 19,1 & 30,3 & 7,2 & 10,9 & 19,9 & 5,1 & 8,4 & 13,9 \\
\hline Densidade $\left(\times 10^{3} \mathrm{~kg} \cdot \mathrm{m}^{-3}\right)$ & 1,13 & 1,06 & 1,06 & 0,73 & 0,60 & 0,69 & 0,52 & 0,46 & 0,48 \\
\hline
\end{tabular}

${ }^{1}$ Lisímetros constituídos em sua totalidade (100\%) de matéria orgânica (denominado de conjunto RSO). ${ }^{2}$ Lisímetros constituídos por $70 \%$ de matéria orgânica (conjunto $\mathrm{RSU}_{\text {intermediário }}$ ). ${ }^{3}$ Lisímetros constituídos por 40\% de matéria orgânica (conjunto RSU). ${ }^{4}$ Lisímetros 1 a 9. Observações: i) L1, L4 e L6, lisímetros com $\emptyset 150 \mathrm{~mm}$; ii) L2, L5 e L8, lisímetros com $\emptyset 200 \mathrm{~mm}$; iii) L3, L6 e L9, lisímetros com $\emptyset 250 \mathrm{~mm}$. ${ }^{5}$ Teoricamente disponível, considerando uma camada de resíduos de 0,60 m. ${ }^{6}$ Retirando o volume ocupado pelo dreno de lixiviado e gás, com $\emptyset 20 \mathrm{~mm}$.

Fonte: Dados da pesquisa (2016)

\subsection{Caracterização físico-química das amostras de resíduos}

Foram realizadas análises físico-químicas, conforme o Standard Methods for the Examination of Water and Wastewater (APHA; AWWA; WEF, 2012), com vistas à caracterização inicial das amostras dos resíduos provenientes das três composições definidas para os experimentos, sendo estas: i) RSO (100\% MO); ii) RSU intermediário (70\% MO) e iii) RSU (40\% MO). Para a caracterização inicial dos resíduos foram analisados os seguintes parâmetros: teor de umidade, sólidos voláteis e $\mathrm{pH}$. Esta caracterização foi realizada em maio de 2016.
Adicionalmente, foram realizadas análises no lixiviado gerado nos lisímetros, ao longo do período de monitoramento, sendo avaliados os parâmetros de pH e DQOO. Inicialmente essa caracterização foi mensal, entre os meses de junho a agosto de 2016; após esse período, essa frequência passou a ser bimestral (outubro/2016, dezembro/2016 e fevereiro/2017). Sendo assim, além da caracterização inicial na fase de enchimento dos lisímetros, foram realizadas 6 campanhas de monitoramento, englobando 270 dias de confinamento dos resíduos nas células experimentais. 


\section{RESULTADOS E DISCUSSÃO}

\subsection{Caracterização físico-química inicial das amostras de resíduos}

$\mathrm{Na}$ Tabela 3 é apresentada a caracterização físico-química inicial das amostras de resíduos provenientes das 3 composições em estudo: i) RSO (100\% MO); ii) RSUintermediário (70\% MO) e iii) RSU (40\% MO).

$\mathrm{Na}$ caracterização físico-química inicial das amostras de resíduos verificou-se que o maior teor de umidade, de $56,76 \%$, foi identificado para a amostra de RSO (Tabela 3). Segundo Melo
(2011), a maior parcela de umidade na massa de resíduos é encontrada nos compostos orgânicos, seguidos pelas frações de papel e papelão, trapos, couros, etc. Bidone e Povineli (1999) afirmam que a umidade dos resíduos aterrados se encontra na faixa de 40 a $60 \%$ para as condições climáticas brasileiras; o que corrobora com os valores determinados para as amostras em estudo (Tabela 3 ). Ressalta-se que essa faixa de umidade é considerada ótima para a atividade de diferentes grupos microbianos e fúngicos (MELO, 2011).

Tabela 3 - Caracterização físico-química inicial das amostras de resíduos provenientes das três diferentes composições em estudo

\begin{tabular}{|c|c|c|c|c|c|c|c|c|c|}
\hline \multirow{2}{*}{ Parâmetros } & \multicolumn{3}{|c|}{ RSO $^{1}$} & \multicolumn{3}{|c|}{$\mathrm{RSU}_{\text {intermediário }}{ }^{2}$} & \multicolumn{3}{|c|}{$\mathrm{RSU}^{3}$} \\
\hline & $\mathrm{L}^{4}{ }^{4}$ & $L 2^{4}$ & $\mathrm{~L}^{4}$ & L4 ${ }^{4}$ & L5 $^{4}$ & $L 6^{4}$ & $\mathrm{~L}^{4}$ & $\mathrm{LB}^{4}$ & L9 \\
\hline Umidade (\%) & \multicolumn{3}{|c|}{56,76} & \multicolumn{3}{|c|}{52,78} & \multicolumn{3}{|c|}{49,12} \\
\hline Sólidos voláteis (\%) & \multicolumn{3}{|c|}{72,51} & \multicolumn{3}{|c|}{75,69} & \multicolumn{3}{|c|}{71,63} \\
\hline $\mathrm{pH}$ & \multicolumn{3}{|c|}{4,77} & \multicolumn{3}{|c|}{5,35} & \multicolumn{3}{|c|}{5,60} \\
\hline
\end{tabular}

${ }^{1}$ Lisímetros constituídos em sua totalidade (100\%) de matéria orgânica (denominado de conjunto RSO). ${ }^{2}$ Lisímetros constituídos por $70 \%$ de matéria orgânica (conjunto RSU ${ }_{\text {intermediário }}$ ). ${ }^{3}$ Lisímetros constituídos por $40 \%$ de matéria orgânica (conjunto RSU). ${ }^{4}$ Lisímetros 1 a 9.

Fonte: Dados da pesquisa (2016)

O teor de sólidos voláteis (SV) para todas as composições de resíduos foi superior a $70 \%$, conforme observado na Tabela 3, o que se configura num indicativo da presença de um elevado percentual de matéria orgânica a ser bioestabilizada (GARCEZ, 2009). Aires (2013), monitorando uma célula experimental de RSU em Campina Grande-PB, com uma composição de 46,5\% de matéria orgânica e volume de $11 \mathrm{~m}^{3}$, verificou teores de sólidos voláteis de $76 \%$. Valores semelhantes foram constatados por Leite (2008) e Ribeiro et al. (2016) com estudos em células experimentais em Campina Grande-PB.

Segundo Röhrs, Fourie e Morris (2003), o SV é um bom parâmetro para indicar a perda de material orgânico em um aterro ao longo do tempo; entretanto, isoladamente, não é um bom indicador do potencial da geração de biogás, quando se trata do RSU em sua totalidade, pois nem todo material volátil é convertido em gás, como é o caso de plástico e borracha.

$\mathrm{O} \mathrm{pH}$ inicial das amostras de resíduos ficou na faixa de 4,7 a 5,6 (Tabela 3). Segundo Alcântara (2007), o pH igual a 6,0 estaria em torno dos padrões normais para o RSU devido ao fato de a maior fração dos resíduos ser composta de resíduos orgânicos. Essa assertiva condiz com o pH de 5,6, obtido para o conjunto de lisímetros da categoria RSU. Entretanto, valores mais ácidos de $\mathrm{pH}$ foram verificados para as demais categorias de lisímetros, em função do maior percentual de matéria orgânica.

\subsection{Geração de lixiviado nos lisímetros}

Na Fig. 4 é ilustrado o volume de lixiviado gerado nos lisímetros em estudo, bem como o acumula- 
do no período monitorado. Verificou-se que nos 2 (dois) meses após o enchimento dos lisímetros houve geração de lixiviado apenas nas células experimentais de RSO. Ressalta-se que essa geração se estendeu por todo o período monitorado.

Após 270 dias de enchimento dos lisímetros, todas as células experimentais do conjunto RSO (100\% $\mathrm{MO})$ e $\mathrm{RSU}_{\text {intermediário }}(70 \% \mathrm{MO})$ geraram líquidos lixiviados, sendo o volume acumulado superior nas células experimentais de resíduos orgânicos, totalizando 857,5, 1.020,5 e 1.656,0 mL em L1, L2 e L3, respectivamente (Fig. 4). Verifica-se que há relação entre a massa de resíduos e o volume de lixiviado gerado, no qual o lisímetro com menor área superficial gerou quantidades inferiores de subprodutos líquidos. Entretanto, não foi verificada uma proporcionalidade entre essas variáveis.

Esses resultados são condizentes com as maiores densidades alcançadas nos lisímetros L1, L2 e L3 (Tabela 4), decorrentes da maior homogeneidade da massa de RSO. Adicionalmente, essa característica dos RSO resulta em uma diminuição de vazios no interior dos lisímetros e favorece a expulsão dos líquidos lixiviados gerados. Outro aspecto a destacar é que essa configuração de lisímetros apresenta maiores quantidades de materiais a serem biodegradados, incrementando a geração de lixiviado.

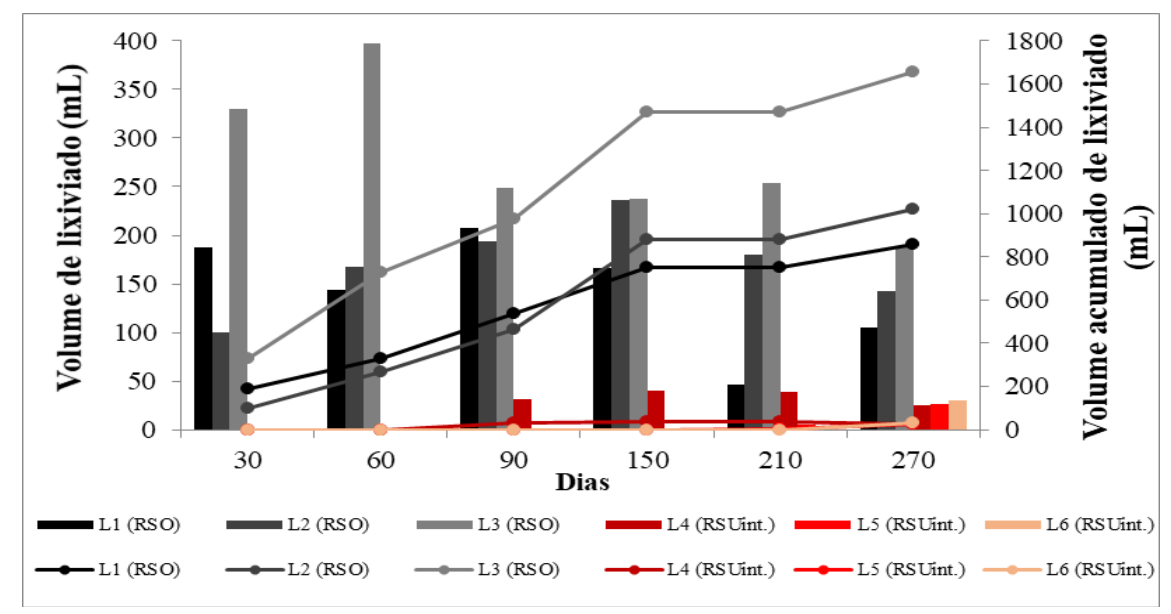

Figura 4 - Evolução temporal do volume de lixiviado nos lisímetros

L1, L2 e L3 - lisímetros constituídos em sua totalidade (100\%) de matéria orgânica (denominado de conjunto RSO). L4, L5 e L6 - Lisímetros constituídos por 70\% de matéria orgânica (conjunto RSUintermediário).

Fonte: Dados da pesquisa (2017)

Tabela 4 - Geração de lixiviado nos lisímetros em estudo

\begin{tabular}{|c|c|c|c|c|}
\hline \multicolumn{2}{|c|}{ Lisímetros } & \multirow{2}{*}{$\begin{array}{c}\text { Mresíduos (kg) } \\
11,1\end{array}$} & \multirow{2}{*}{$\begin{array}{c}\text { Densidade }\left(\mathbf{x} 10^{3} \mathbf{~ k g} \cdot \mathbf{m}^{-3}\right) \\
1,13\end{array}$} & \multirow{2}{*}{$\begin{array}{c}\text { Vlixiviado }(\mathrm{mL}) \\
857,5\end{array}$} \\
\hline \multirow{3}{*}{$\mathrm{RSO}^{1}$} & $\mathrm{~L}^{4}$ & & & \\
\hline & $\mathrm{L}^{4}$ & 19,1 & 1,06 & $1.020,5$ \\
\hline & $\mathrm{L}^{4}$ & 30,3 & 1,06 & $1.656,0$ \\
\hline \multirow{3}{*}{$\mathrm{RSU}_{\text {intermediário }}{ }^{2}$} & $\mathrm{~L}^{4}$ & 7,2 & 0,73 & 136,0 \\
\hline & $\mathrm{L}^{4}$ & 10,9 & 0,60 & 31,2 \\
\hline & $\mathrm{L}^{4}$ & 19,9 & 0,69 & 30,0 \\
\hline \multirow{3}{*}{$\mathrm{RSU}^{3}$} & $\mathrm{L7}^{4}$ & 5,1 & 0,52 & 0,0 \\
\hline & $\mathrm{LB}^{4}$ & 8,4 & 0,46 & 0,0 \\
\hline & $\mathrm{L}^{4}$ & 13,9 & 0,48 & 0,0 \\
\hline
\end{tabular}

'Lisímetros constituídos em sua totalidade (100\%) de matéria orgânica (denominado de conjunto RSO). ${ }^{2}$ Lisímetros constituídos por $70 \%$ de matéria orgânica (conjunto RSU ). ${ }^{3}$ Lisímetros constituídos por $40 \%$ de matéria orgânica (conjunto RSU). ${ }^{4}$ Lisímetros 1 a 9.

Fonte: Dados da pesquisa (2017). 
No conjunto $\mathrm{RSU}_{\text {intermediário }}$ verificou-se uma relação inversa entre a área superficial dos lisímetros e o volume de lixiviado. Em L4, a maior quantidade de subproduto líquido pode estar associada à maior dificuldade de compactação dos resíduos na célula experimental, em virtude de sua reduzida área superficial. Isso dificultou a distribuição e acomodação dos materiais, resultando em caminhos preferenciais para a percolação do lixiviado (Tabela 4).

Por meio dos resultados apresentados na Tabela 4, evidencia-se a influência da composição dos resíduos (Fig. 2) na geração dos líquidos lixiviados, em especial das categorias papel e papelão e têxteis sanitários, que podem atuar como materiais absorventes dos líquidos gerados. Tal aspecto é evidenciado ao se comparar a geração de lixiviado nos lisímetros dos conjuntos $\mathrm{RSU}_{\text {intermediário }} \mathrm{e}$ RSU, com 10,6 e $21,2 \%$ desses materiais, respectivamente. Sendo assim, verifica-se que o elevado percentual de materiais com capacidade de retenção de líquidos nos lisímetros de RSU, associado às condições meteorológicas da região, pode ter contribuído para que a capacidade de campo dos resíduos não fosse excedida e, consequentemente, impediu a percolação do lixiviado gerado no processo biodegradativo.

Por meio de estudos realizados por Silva (2016) em um lisímetro de RSU com volume de $11 \mathrm{~m}^{3}$, localizado em Campina Grande-PB, foi verificado que não houve a geração de líquidos lixiviados. Para as células experimentais em estudo, com composição de RSU típica desse mesmo município (caso dos lisímetros L7, L8 e L9), não se verificou a percolação de lixiviado depois de 270 dias de monitoramento; o que corrobora o fato de que o resíduo de Campina Grande, apesar de apresentar umidade inicial elevada (Tabela 3), opera sob a condição de túmulos secos climáticos.
Adicionalmente, as baixas densidades alcançadas nos lisímetros de RSU, quando comparadas às demais células experimentais, estão relacionadas ao percentual de plásticos (Tabela 4). 0 maior percentual em massa de plásticos no conjunto RSU, de 18,7\%, embora reduzido quando comparado com o percentual de matéria orgânica (40\%), é expressivo em termos de variação de volume, quando do processo de compactação.

De acordo com estudos realizados por Araújo Neto (2016), que obteve a composição gravimétrica do município de Campina Grande-PB utilizada como base para esta pesquisa, a fração de plásticos representou um percentual em massa de $16,7 \%$, sendo que em termos volumétricos dos resíduos soltos e compactos esse percentual atingiu 53,5 e 39,2\%, respectivamente. Já os resíduos orgânicos, materiais de baixa compressibilidade, obtiveram um percentual em massa de $46,5 \%$, e em termos volumétricos esse percentual aumentou de 14,6 para $24,5 \%$, após a compactação.

Tais resultados refletem a influência, também, da categoria dos plásticos na retenção da umidade gerada pelo processo biodegradativo dos resíduos, uma vez que esse material, por ocupar quase a metade do volume dos lisímetros do conjunto RSU, pode favorecer a formação de obstáculos que impedem a percolação de líquidos lixiviados.

Diante do exposto, ressalta-se que os resultados obtidos são indicativos, também, da influência da reduzida contribuição pluviométrica do período em estudo, que durante a primeira etapa do monitoramento (150 dias iniciais) foi de 147,0 $\mathrm{mm}$, associada aos elevados índices de evaporação, de $626 \mathrm{~mm}$, quando considerada uma média histórica para o período maio a outubro, conforme Fig. 5 (AESA, 2017; PARAÍBA, 2001). 


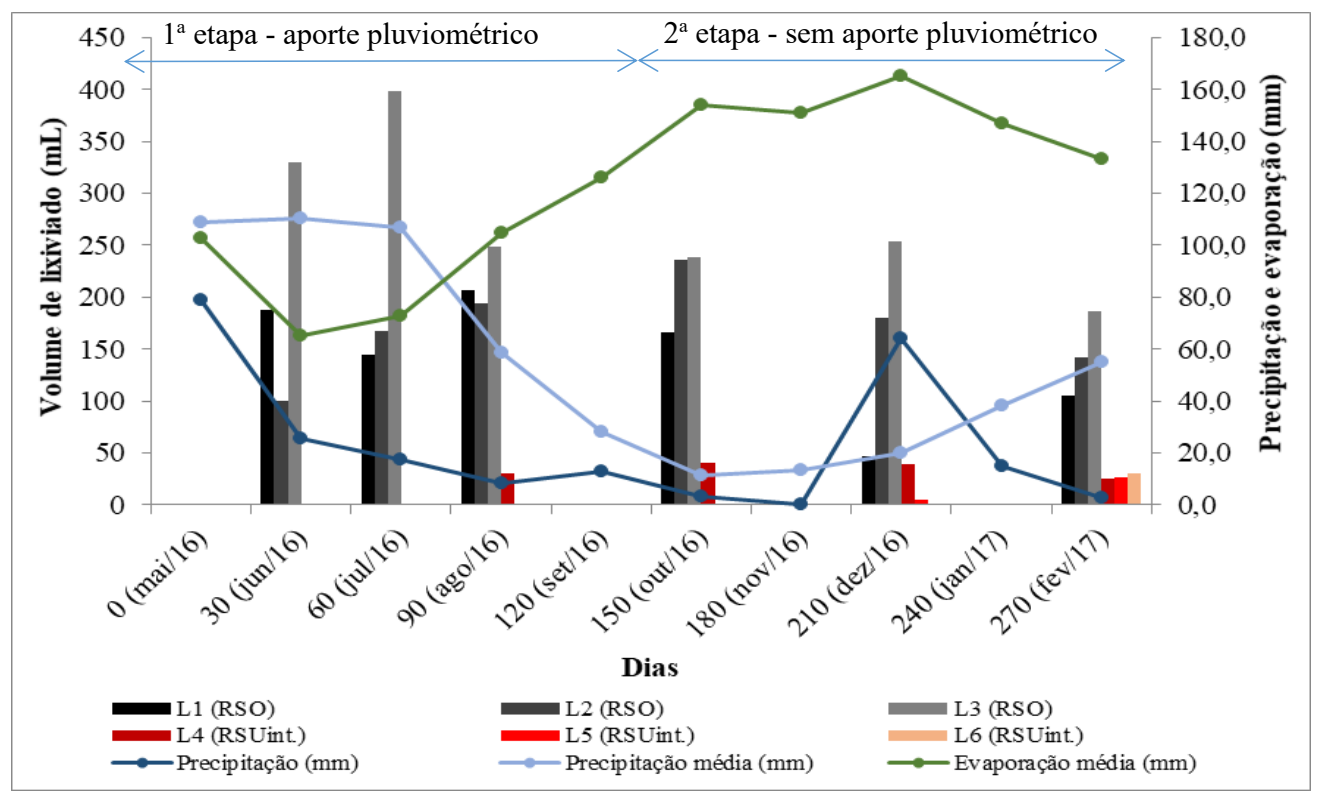

Figura 5 - Volume de lixiviado nos lisímetros e dados hidrometeorológicos

L1, L2 e L3 - lisímetros constituídos em sua totalidade (100\%) de matéria orgânica (denominado de conjunto RSO). L4, L5 e L6 - Lisímetros constituídos por 70\% de matéria orgânica (conjunto RSU

Fonte: Dados da pesquisa (2017); AESA (2017); PARAíBA (2001).

Essas condições de baixas contribuições pluviométricas, associadas ao solo utilizado na camada de cobertura dos lisímetros (CL - argila inorgânica de mediana plasticidade, classificação do SUCS (ASTM D2487-11)), com coeficientes de permeabilidade à água, in situ e em laboratório, da ordem de $10^{-8} \mathrm{~m} \cdot \mathrm{s}^{-1}$ (ARAÚJO, 2017), conferiram ao sistema baixa taxa de infiltração. Certamente esses fatores influenciaram, também, na evolução do processo biodegradativo dos RSU, visto que a umidade disponível ao sistema foi oriunda, majoritariamente, dos resíduos.

Além disso, evidencia-se o efeito de escala dos lisímetros quando comparados, por exemplo, com uma célula do Aterro Sanitário em Campina Grande-PB. Ressalta-se que: i) a massa de resíduos no lisímetro de maior diâmetro e densidade, 30,3 kg em L3, é mais de 2 milhões de vezes inferior à massa de resíduos da Célula 2 do aterro, que é de 62.359.438,0 kg; ii) a área superficial da camada de cobertura dos lisímetros de maior diâmetro é de $0,04909 \mathrm{~m}^{2}$, cerca de 8 mil vezes menor que a da Célula do aterro, em torno de $400 \mathrm{~m}^{2}$; iii) o peso próprio da camada de cobertura, que nos lisímetros em estudo é de 0,20 m e na célula do aterro varia de 0,80 a 1,40m, o qual interfere na tensão aplicada no resíduo e consequente geração de lixiviado.

Um fator a se levar em consideração é a razão área superficial/volume. Quando a área superficial é maior que o volume, têm-se maiores trocas de energia e matéria com o meio. Nesse sentido, na estação de seca, há uma interferência maior nos lisímetros se comparado com aterros nas mesmas condições pluviométricas. Assim, em um aterro sanitário em escala real, as trocas de energia e matéria são menores do que em um lisímetro, pois este tem uma área superficial muito maior se comparado ao aterro. 


\subsection{Caracterização físico-química do lixiviado} no decorrer do monitoramento dos lisímetros

\subsection{1 $\mathrm{pH}$}

A caracterização físico-química do lixiviado foi resubprodutos líquidos no período do monitoramento. alizada somente paras os lisímetros que geraram

Os valores de pH obtidos estão ilustrados na Fig. 6.

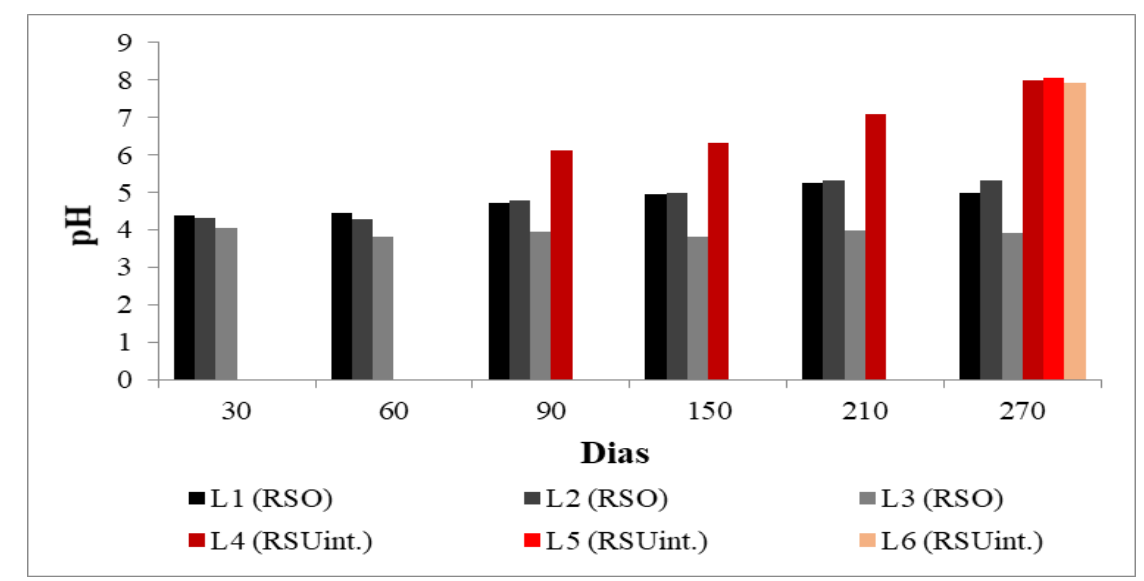

Figura 6 - Evolução temporal do pH nos lisímetros que geraram lixiviado

L1, L2 e L3 - lisímetros constituídos em sua totalidade (100\%) de matéria orgânica (denominado de conjunto RSO). L4, L5 e L6 - Lisímetros constituídos por 70\% de matéria orgânica (conjunto RSU intermedíáro $_{\text {). }}$

Fonte: Dados da pesquisa (2017)

Verifica-se que o conjunto de lisímetros de RSO, único que gerou lixiviado desde os primeiros dias de monitoramento, permaneceu com o $\mathrm{pH}$ baixo durante todo o período em estudo, não atingindo valor superior a 5,5 (Fig. 6). Zhai et al. (2015) investigaram, em laboratório, o efeito de diferentes valores de $\mathrm{pH}$ inicial $(6,0 ; 6,5 ; 7,0 ; 7,5$ e 8,0) e um pH inicial sem controle na digestão anaeróbia de resíduos de cozinha, inoculado com esterco bovino. Os resultados mostraram que os reatores com $\mathrm{pH}$ inicial sem controle e $\mathrm{pH}$ inicial de 6,0 não atingiram a fase metanogênica. Os valores de $\mathrm{pH}$ dos outros reatores atingiram valores de 7,7 a 7,9, com significativo aumento na geração de metano.

Resultados semelhantes aos obtidos por Zhai et al. (2015), para os reatores com pH inicial sem controle e pH inicial 6 , foram verificados nos li- símetros de RSO deste estudo, uma vez que o $\mathrm{pH}$ nesse conjunto se manteve ácido durante os 270 dias de monitoramento.

Após 90 dias foi verificada a geração de lixiviado no lisímetro L4, e somente após 270 dias o L5 e L6 geraram subprodutos líquidos. Dessa forma, o $\mathrm{pH}$ nesses lisímetros apresentou valores mais elevados, em torno de 8,0 (Fig. 6), indicando, a princípio, condições favoráveis ao desenvolvimento da fase metanogênica de biodegradação.

\subsubsection{DQO}

Os valores de DQQ para os lisímetros que geraram lixiviado, no período em análise, estão ilustrados na Fig. 7. Elevados valores de DQO, superiores a $120.000 \mathrm{mgO}_{2} \cdot \mathrm{L}^{-1}$, foram verificados nos lisímetros de RSO (L1, L2 e L3), em todo o período 
monitorado (Fig. 7). Segundo O'Leary e Tchobanoglous (2002), a DQO na fase acidogênica aumenta de forma significativa devido à dissolução dos ácidos orgânicos no lixiviado, o que promove a redução do $\mathrm{pH}$ para valores ácidos, conforme verificado no conjunto RSO (Fig. 6).

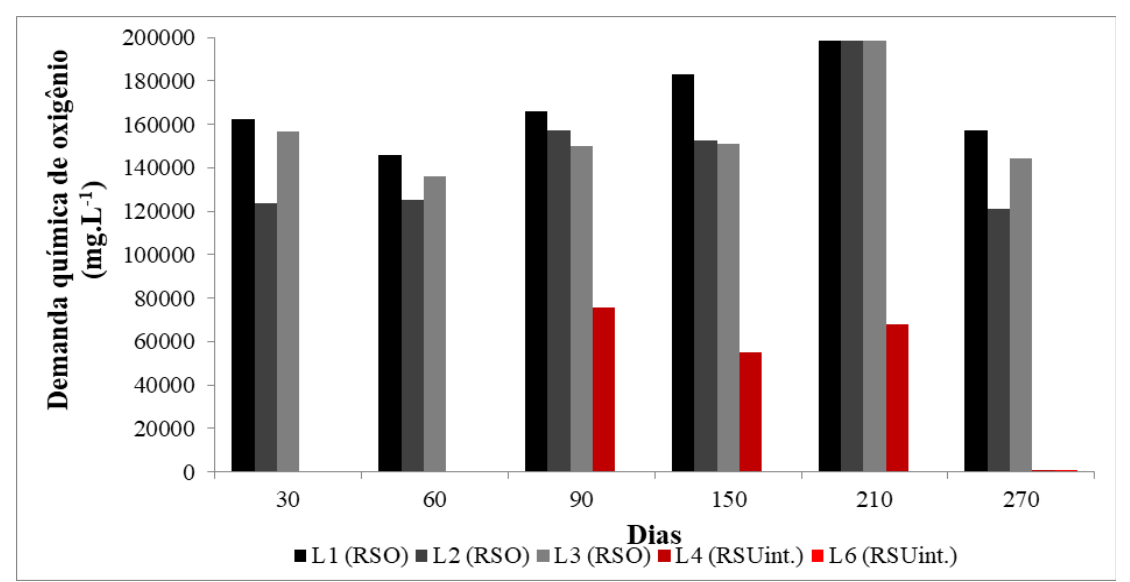

Figura 7 - Concentrações de demanda química de oxigênio do lixiviado nos lisímetros L1, L2 e L3 - lisímetros constituídos em sua totalidade (100\%) de matéria orgânica (denominado de conjunto RSO). L4 e L6 - Lisímetros constituídos por 70\% de matéria orgânica (conjunto RSU Fonte: Dados da pesquisa (2017)

Quanto ao conjunto $\mathrm{RSU}_{\text {intermediário }}(70 \% \mathrm{MO})$, no período de 90 a 210 dias, o lisímetro L4 obteve valor máximo de $\mathrm{DQO}$ de $75.889 \mathrm{mgO}_{2}$. $\mathrm{L}^{-1}$ (Fig. 7). Nesse período, o $\mathrm{pH}$ do lixiviado em $L 4$ variou entre 6,13 e 7,10, aumentando com o decorrer do tempo (Fig. 6). Alcântara (2007) obteve em lisímetros experimentais de RSU um valor máximo de DQO de $72.900 \mathrm{mgO}_{2}$. $\mathrm{L}^{-1}$. Durante os 100 dias iniciais de monitoramento desses lisímetros, observou-se uma tendência de elevação dos valores de DQOO. Com o passar do tempo, esses valores decresceram acentuadamente, sendo constatados valores entre 1.400 a $350 \mathrm{mgO}_{2} \cdot \mathrm{L}^{-1}$, depois de decorridos 193 dias de aterramento dos resíduos.

Com o decorrer do monitoramento dos lisímetros do presente estudo, os valores da DQQ tenderam a decrescer, em virtude da diminuição do índice de material orgânico, levando em consideração a biodegradação do resíduo. No lisímetro $L 4$, após 270 dias, houve uma redução expressiva de DQQO, atingindo o valor de $806 \mathrm{mgO}_{2} \cdot \mathrm{L}^{-1}$, acompanhado de uma elevação do pH para 8,0; caracterizando, dessa forma, um ambiente alcalino.

Apesar de o lisímetro L5 ter gerado lixiviado, após 270 dias de monitoramento, em função do pequeno volume coletado, não foi possível analisar o parâmetro DQ O. Não obstante, como L4, L5 e L6, após 270 dias, estavam na mesma faixa de $\mathrm{pH}(8,0,8,08$ e 7,94, respectivamente), e como o valor de DQO de L4 e L6 foi de $806 \mathrm{mgO}_{2}$. $\mathrm{L}^{-1}$; provavelmente, um valor reduzido de DQO, próximo a $800 \mathrm{mgO}_{2} \cdot \mathrm{L}^{-1}$, seria registrado em $\mathrm{L} 5$.

\section{CONCLUSÕES}

- A baixa geração de lixiviado nos lisímetros do conjunto $\mathrm{RSU}_{\text {intermediário }}$ e a não geração de lixiviado no conjunto RSU está associada à maior heteregeneidade desses resíduos, o que implicou em baixas densidades, quando comparadas com os lisímetros de RSO; e, consequentemente, em uma menor massa disponível para ser metabolizada pelos microrganismos. 
- A categoria de materiais relacionados a papel e papelão e têxteis sanitários pode exercer uma capacidade de absorção da umidade no interior dos lisímetros, impedindo parcialmente sua percolação.

- Os plásticos, por ocuparem quase a metade do volume dos lisímetros, configuram-se como obstáculo na percolação do lixiviado.

- No conjunto RSO houve uma acidificação do meio, uma vez que não foi adicionado nenhum tipo de inóculo para tamponar o pH.

\section{AGRADECIMENTOS \\ À ECOSOLO - Gestão Ambiental de Resíduos Ltda.}

\section{CONTRIBUIÇÃO DOS AUTORES}

Todos os autores contribuíram de forma igualitária.

\section{REFERÊNCIAS}

ABRELPE - Associação Brasileira de Empresas de Limpeza Publica e Resíduos Especiais. Panorama dos Resíduos Sólidos no Brasil 2015. São Paulo: ABRELPE, 2015, 92 p.

AESA - Agência Executiva de Gestão das Águas do Estado da Paraíba. Monitoramento. Disponível em: <http://www.aesa. pb.gov.br/>. Acesso em out. 2017.

AIRES, K. O. Monitoramento das concentrações de gases em uma célula experimental de resíduos sólidos urbanos na cidade de Campina Grande - PB. Dissertação (Mestrado em Engenharia Civil e Ambiental). Programa de Pós-Graduação em Engenharia Civil e Ambiental, Universidade Federal de Campina Grande, Campina Grande-PB, 2013.

ALCÂNTARA, P. B. Avaliação da influência da composição de resíduos sólidos urbanos no comportamento de aterros simulados. Tese (Doutorado em Engenharia Civil). Universidade Federal de Pernambuco, Recife-PE, 2007.

APHA; AWWA; WEF. Standard methods for the examination of water and wastewater. 22 ed. Washington: APHA, 2012, 1496 p.

ARAÚJO NETO, C. L. Análise do comportamento dos resíduos sólidos urbanos e desenvolvimento de modelos estatísticos para previsão das deformações de aterros sanitários. Dissertação (Mestrado em Engenharia Civil e Ambiental). Universidade Federal de Campina Grande, Campina Grande-PB, 2016.
ARAUJO, P. S. Análise do desempenho de um solo compactado utilizado na camada de cobertura de um aterro sanitário. Dissertação (Mestrado em Engenharia Civil e Ambiental). Universidade Federal de Campina Grande, Campina GrandePB, 2017.

BARLAZ, M. A.; HAM, R. K.; SCHAEFER, D. M.; ISAACSON, $R$. Methane production from municipal refuse: a review of enhancement techniques and microbial dynamics. Critical Reviews in Environmental Control, v. 19, n. 6, 1990, p. 557-584. https://doi.org/10.1080/10643389009388384

BIDONE, F. R. A.; POVINELLI, J. Conceitos básicos de resíduos sólidos. São Carlos: EESS/USP, 1999. 120p.

CHEN, K. Y.; CHENG, J. J.; CREAMER, K. S. Inhibition of anaerobic digestion process: a review. Bioresource Technology, v. 99, 2008, p. 4044-4064. https://doi.org/10.1016/j.biortech.2007.01.057

DAYANTHI, W. K. C. N. Pretreatment of solid waste by enhanced leachin. MTech thesis, Asian Institute of Technology, Thailand, 2003.

ECOSOLO - GESTÃO AMBIENTAL DE RESÍDUOS Ltda. Dados do monitoramento do Aterro Sanitário de Campina Grande. 2016. (Documento impresso).

GARCEZ, L. R. Estudo dos componentes tóxicos em um biorreator de resíduos sólidos urbanos da cidade de Campina Grande-PB. Dissertação (Mestrado Engenharia Civil e Ambiental). Universidade Federal de Campina Grande, Campina Grande-PB, 2009.

IBGE - INSTITUTO BRASILEIRO DE GEOGRAFIA E ESTATÍSTICA. Cidades. 2010. Disponível em: <http://www.cidades.ibge.gov. br>. Acesso em: set. 2019.

HIGUCHI, T. Look back over the studies of lignin biochemistry. Journal of Wood Science, v. 52, n. 1, 2006, p. 2-8. https://doi. org/10.1007/s10086-005-0790-z

JAYASINGHE, P. A.; HETTIARATCHI, J. P. A.; MEHROTRA, A. K.; KUMAR, S. Effect of enzyme additions on methane production and lignin degradation of landfilled sample of municipal solid waste. Bioresource Technology, v. 102, 2011, p. 4633-4637. https://doi.org/10.1016/j.biortech.2011.01.013

LASKRI, N.; NEDJAH, N. Comparative study for biogas production from different wastes. International Journal of Bio-Science and Bio-Technology, v. 7, n. 4, 2015, p.39-46. https://doi. org/10.14257/ijbsbt.2015.7.4.05

LEE, G. F.; JONES-LEE, A. Flawed Technology of Subtitle D Landfilling of Municipal Solid Waste. G. Fred Lee \& Associates, 2015.

LEITE, H.E.A.S. Estudo do comportamento de aterros de RSU em um biorreator em escala experimental na cidade de Campina Grande - Paraíba. Dissertação (Mestrado em Engenharia Civil e Ambiental). Universidade Federal de Campina Grande, Campina Grande-PB, 2008. 
MELO, M. C. Estudo da matéria orgânica nos recalques de resíduos sólidos urbanos aterrados. Tese (Doutorado em Ciência e Engenharia de Materiais). Universidade Federal de Campina Grande, Campina Grande-PB, 2011.

MORA-NARANJO, N.; MEIMA, J. A.; HAARSTRICK, A.; HEMPEL, D. C. Modelling and experimental investigation of environmental influences on the acetate and methane formation in solid waste. Waste Management, v. 24, 2004, p. 763-773. https://doi. org/10.1016/j.wasman.2004.04.006

O'LEARY, P. R; TCHOBANOGLOUS, G. Landfilling, Chapter 14. In: TCHOBANOGLOUS, G.; KREITH, F. (Eds). Handbook of Solid Waste Management, 2 ed., McGraw-Hill, 2002.

PARAÍBA. Pro-Água: Semi-Árido. Plano Diretor de Recursos Hídricos da Bacia Hidrográfica do Rio Paraíba: Relatório Final de Diagnóstico: Tomo I. SEMARH: 2001.

RAPOSO, F.; DE LA RUBIA, M. A.; FERNÁNDEZ-CEGRÍ, V.; BORJA, R. Anaerobic digestion of solid organic substrates in batch mode: An overview relating to methane yields and experimental procedures. Renewable and Sustainable Energy Reviews, v. 16, 2011, p. 861-877. https://doi.org/10.1016/j.rser.2011.09.008

RIBEIRO, L. S.; SILVA, A. S.; ALVES, F. S.; MELO, M. C; PAIVA, W.; MONTEIRO, V. E. D. Monitoramento físico-químico de um biorreator com resíduos sólidos urbanos em escala piloto na cidade de Campina Grande (PB). Engenharia Sanitária e Ambiental (Online), v. 21, n. 1, 2016, p. 1-9. https://doi. org/10.1590/S1413-41520201600100110157

RÖHRS, L. H.; FOURIE, A. B.; MORRIS, J. F. W. Gas potential and the state of decay of MSW. In: Proc. Sardinia 2003, Ninth International Waste Management and Landfill Symposium, Cagliari, Italy, 2003. Anais...

SANCHEZ, C. Lignocellulosic residues: Biodegradation and bioconversion by fungi. Biotechnology Advances, v. 27, n. 2, 2009, p. 185-194. https://doi.org/10.1016/j. biotechadv.2008.11.001

SETHI, S.; KOTHIYAL, N. C.; NEMA, A. K. Stabilisation of municipal solid waste in bioreactor landfills - an overview. International Journal Environment and Pollution, v. 51, n. 1/2, 2013, p. 5778. https://doi.org/10.1504/IJEP.2013.053175

SILVA, A. S. Análise de componentes tóxicos em resíduos sólidos urbanos. Tese (Doutorado em Ciência e Engenharia de Materiais). Universidade Federal de Campina Grande, Campina Grande-PB, 2016.

ZHAI, N.; ZHANG, T.; YIN, D.; YANG, G.; WANG, X.; REN, G.; FENG, $Y$. Effect of initial $\mathrm{pH}$ on anaerobic co-digestion of kitchen waste and cow manure. Waste Management, 38, 2015, p. 126-131. https://doi.org/10.1016/j.wasman.2014.12.027 